\title{
Ties that Bind
}

I regret the gradual obsolescence of the tie. A tie keeps my neck warm but does not overheat it like a polo neck. It also enables me to advertise my exquisite taste and to liven up other people's days. So this morning I was standing in front of the mirror tying my most recently acquired example, in preparation for being consulted on some radical change proposals. I chose a particularly provocative pink tie which proclaims, in black, "What is the evidence for your statement?" This seems to me to be a particularly pertinent question for our times, so I thought I would share with you some of the occasions when it would have been so good to have it asked (and even better to have it answered). These include:

- when the oil industry said "this oil pipeline cannot leak," and that pipelines operate more safely than any other mode of oil transportation (but ....);

- when, 40 years ago, we were assured that we would have fusion power in 40 years;

- when many governments signed up to impossibly challenging $\mathrm{CO}_{2}$ reduction levels by 2020;

- when my colleague gave a student a 95\% mark for his project;

- when the car salesman assured me that a new glass treatment would prevent insects from sticking to my windscreen (or your windshield);

- when my government assured me that tighter regulation, together with "efficiency gains" would improve the quality of education ( ...or insert your own choice of issue ...);

- when air transport authorities told airlines that they should not fly through volcanic ash because it was not safe;

- when my colleagues told me "you can't do that because the accreditation panel won't like it";

- when a huge number of researchers told us in their grant applications that nanotubes would radically transform the world;

- when a politician told us that there is a specific and sure route out of recession (his route, natch);

- when the dentist told me "this won't hurt much";

- when my taxi driver in Washington told me that steel was not very important because we've got lots of plastics now;

- when the advertisement assured me that potatoes kept in this dark bag would not sprout;

- when every IT provider berates me that my password is only secure if I change it every three months (despite the fact that I currently have about 40 passwords and if I were to change them four times a year I would need 160 passwords per year-which of course I have to write down);

- when a colleague tells me that if a student is not given a mark for something, she will not learn it (although she learned how to use Facebook without the incentive of a mark!);

- when a major car manufacturer assured the world's press that this is only a very rare and not at all dangerous mechanical problem; and

- when a computer guru told me that I would never need to print anything like this article on paper in order to review and revise it.

Returning to the ties that bind, I assert that nobody can now tie a bow tie. My evidence is that at a recent "black tie" function I spotted only two hand-tied ties-mine, and the one I had tied on a friend. I rest my case. 